\title{
Impact of Abdominal Follow-Up Sonography in Trauma Patients Without Abdominal Parenchymal Organ Lesion or Free Intraabdominal Fluid in Whole-Body Computed Tomography
}

\author{
Nutzen einer abdominellen Verlaufs- \\ Ultraschalluntersuchung bei Traumapatienten ohne \\ Nachweis von Organverletzungen oder freier Flüssigkeit in \\ der initialen Computertomografie
}

Authors

Emmanuel Schneck ${ }^{1}$, Christian Koch ${ }^{1}$, Mara Borgards ${ }^{1}$, Martin Reichert ${ }^{2}$, Andreas Hecker², Christian Heiß3 , Winfried Padberg²,

Enrique Alejandre-Lafont ${ }^{4}$, Rainer Röhrig', Gabriele Anja Krombach ${ }^{4}$, Markus Weigand ${ }^{1}$, Michael Bernhard ${ }^{5}$, Fritz Christian Roller ${ }^{4}$

Affiliations

1 Anesthesiology and Intensive Care Medicine, Justus-Liebig-University Giessen, Germany

2 Department of General and Thoracic Surgery, Justus-Liebig-University Giessen, Germany

3 Department of Trauma Surgery, Justus-Liebig-University Giessen, Germany

4 Diagnostic and Interventional Radiology, Justus-Liebig-University Giessen, Germany

5 Central Emergency Unit, University Hospital Leipzig, Germany

Key words

trauma, ultrasound, FAST, tertiary trauma survey

received 27.3.2016

accepted 14.10 .2016

\section{Bibliography}

DOI http://dx.doi.org/10.1055/s-0042-120844

Published online: 2017 | Fortschr Röntgenstr 2017; 189: 128-136

(c) Georg Thieme Verlag KG Stuttgart · New York

ISSN 1438-9029

\section{Correspondence}

Herr Dr. Fritz Christian Roller

Radiologie, Universitätsklinikum Giessen

Klinikstraße 36

35392 Giessen

Germany

Tel.: ++ 49/641/98556329

Fax: ++49/641/98541809

fritz.c.roller@radiol.med.uni-giessen.de

\section{ABSTRACT}

Purpose Patients suffering from severe blunt abdominal trauma are challenging because of their need for accurate diagnostic imaging and fast therapeutic action. Whole-body computed tomography (WBCT) is highly sensitive and represents the gold standard in the trauma room diagnostic setting. The aim of our study was to investigate the impact and therapy relevance of abdominal follow-up sonography (AFS) as part of the tertiary trauma survey (TTS) in patients without abdominal parenchymal organ lesions or free abdominal fluid in initial WBCT.

Materials and Methods All adult patients without abdominal parenchymal organ lesions or free intraabdominal fluid in the initial WBCT examination, who received AFS within 24 hours after trauma, were included in this retrospective analysis between January 2008 and December 2011.

Results 316 patients were analyzed (ISS $10 \pm 8$, NISS $13 \pm 11$ ) according to the inclusion criteria. Overall, only small amounts of free intraabdominal fluid were detected in AFS in 3 patients (0.9\%) and remained without therapeutic consequence. None of the patients died due to intraabdominal bleeding. Conclusion AFS as part of the TTS did not show additional benefits and had no impact on further treatment in patients without abdominal parenchymal organ lesions or free intraabdominal fluid in the initial WBCT examination. We conclude that AFS is not routinely required but should be performed if indicated on a clinical or laboratory basis because of its fast and less invasive character.

\section{Key points}

- Seriously injured patients are challenging for medical imaging and treatment.

- Whole-body computed tomography is known for its high accuracy in trauma patients.

- Nonetheless, missed injuries are a major challenge in trauma patients.

- Therefore, follow-up ultrasound is often performed within the tertiary trauma survey.

- Follow-up ultrasound in patients with an inconspicuous abdominal computed tomography scan did not show any benefit.

Citation Format

- Schneck E, Koch C, Borgards M et al. Impact of Abdominal Follow-Up Sonography in Trauma Patients Without Abdominal Parenchymal Organ Lesion or Free Intraabdominal Fluid in Whole-Body Computed Tomography. Fortschr Röntgenstr 2017; 189: 128-136

\section{ZUSAMMENFASSUNC}

Ziel Das Management von Patienten mit schwerem Bauchtrauma ist oft sehr schwierig und erfordert eine möglichst schnelle akkurate Bildgebung und Behandlung. Die Ganzkörper-Computertomografie (GK-CT) stellt den Goldstandard zur Diagnostik solcher Patienten dar. Ziel unserer Studie war es den Nutzen des Verlaufsultraschalls im Rahmen des „Tertiary Trauma Survey (TTS) “ bei Patienten ohne abdominelle Parenchymorganläsion oder freie Flüssigkeit im initialen GK-CT zu evaluieren. 
Material und Methoden In die retrospektive Studie wurden zwischen Januar 2008 und Dezember 2011 alle erwachsenen Patienten ohne Parenchymorganläsion oder freie Flüssigkeit im initialen GK-CT, die einen Verlaufsultraschall innerhalb von 24 Stunden nach dem Trauma erhielten, eingeschlossen. Ergebnisse Insgesamt 316 Patienten konnten für die Analyse herangezogen werden (ISS $10 \pm 8$, NISS $13 \pm 11$ ). Im Verlaufsultraschall zeigten sich bei lediglich 3 Patienten $(0,9 \%)$ sehr geringe Mengen an freier Flüssigkeit, welche aber ohne jegliche weitere therapeutische Konsequenz verblieben. Keiner der Patienten starb an einer intraabdominellen Blutung.

Schlussfolgerung Der Verlaufsultraschall im Rahmen des TTS zeigte keinen diagnostischen Nutzen und hatte keinen Einfluss auf Patientenfolgebehandlungen bei Traumapatienten ohne Nachweis einer Parenchymorganverletzung oder freier Flüssigkeit im initialen GK-CT. Somit schlussfolgern wir, das ein Verlaufsultraschall bei diesem Patientenkollektiv nicht routinemäßig durchgeführt werden sollte, aber jederzeit falls klinisch oder laborchemisch erforder- lich auch aufgrund der geringen Invasivität und der schnellen Verfügbarkeit erfolgen kann.

\section{Kernaussagen}

- Schwerverletzte Patienten stellen Bildgebung und Behandlung vor eine große Herausforderung.

- Die Ganzkörper-CT zeichnet sich bei Schwerstverletzten durch ihre hohe diagnostische Genauigkeit aus.

- Trotzdem stellen übersehene Befunde im CT eine große Herausforderung bei Schwerstverletzten dar.

- Im Rahmen des „Tertiary Trauma Survey“ wird deshalb häufig eine Verlaufsultraschalluntersuchung durchgeführt.

- Die Verlaufsultraschalluntersuchung zeigte bei Patienten mit unauffälliger abdomineller CT aber keinen zusätzlichen Nutzen.

\section{Introduction}

Patients suffering from severe blunt abdominal trauma are challenging for emergency room management. These patients need immediate and accurate diagnostic imaging as well as fast therapeutic action. In accordance with existing trauma guidelines, whole-body computed tomography (WBCT) represents the gold standard for emergency diagnosis in the trauma bay [1, 2]. WBCT provide a rapid diagnosis tool, which reduces mortality in severely injured patients [3-6]. Recently, in a large multicenter study, Huber-Wagner et al. demonstrated the potential benefits of WBCT even in hemodynamically unstable trauma patients with increased survival due to the speed and high diagnostic quality of modern CT scanners [7].

The focused assessment with CT in trauma (FACTT) protocol reduces the number of missed injuries (MI) in comparison to sonography and conventional radiologic diagnostic imaging alone [4, 5, 8 -10]. However, previous studies reported an incidence of $\mathrm{MI}$ between 1.9-39\% [11] and missed abdominal injuries (MAI) between $0.06-15 \%$ [12-14]. Therefore, abdominal follow-up sonography (AFS) during tertiary trauma survey (TTS) was implemented in international trauma guidelines [15-22]. However, there is only poor evidence for AFS as part of TTS, and therefore the role of AFS is still unclear. Critics stated that AFS may be too time-consuming and expensive and its benefit has not yet been sufficiently examined [20].

The aim of this study is to analyze trauma patients without abdominal parenchymal lesions or free intraabdominal fluid in the initial WBCT within emergency room management in order to assess the impact of AFS on therapy, clinical progress and patient outcome.

\section{Materials and Methods}

\section{Study Design}

In this retrospective single-center cohort analysis, all patients at an university hospital and level I trauma center between January 2008 and December 2011 were screened for trauma room admission, performed WBCT and conducted AFS within 24 hours after hospital admission as part of the TTS. Patients were checked for inclusion and exclusion criteria, then clinical and radiographic data were collected and finally descriptive analysis was performed. The study was approved by the local ethics committee.

\section{Inclusion and exclusion criteria}

During the four-year study period, all adult patients who underwent WBCT without evidence of free intrabdominal fluid or abdominal parenchymal organ lesions, and who also received an AFS scan within 24 hours after hospital admission during TTS, were included. The exclusion criteria were pediatric patients (age $<18$ years), free intraabdominal fluid or abdominal parenchymal organ lesions in WBCT ( $\triangleright$ Fig. 1 ).

\section{Variables}

The patient characteristics included age and gender, length of stay (ICU and hospital), 24-hour mortality, 30-day mortality, and hospital mortality. The incidence of pathological findings in the AFS as well as secondary bleeding events (e.g. intra-abdominal bleeding within 24 hours) were recorded.

The prehospital dataset included blood pressure, Glasgow Coma Scale (GCS), cardiopulmonary resuscitation (CPR), intuba-

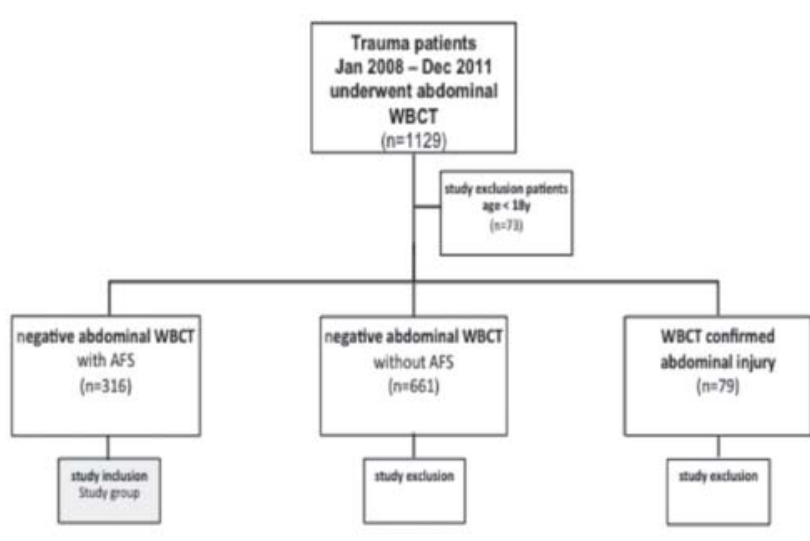

- Fig. 1 Presentation of the study design. Abbreviations: WBCT: whole-body computed tomography, AFS: abdominal follow-up sonography.

- Abb. 1 Darstellung des Studiendesigns. 
tion, and the accident mechanism. The emergency room data record included documentation of injury severity (e. g., abbreviated injury scale (AIS), injury severity score (ISS), new ISS (NISS)). Moreover, intubation rate, CPR, and blood transfusion (massive transfusion was defined as more than 9 units of red blood cells (RBC) were accessed. The ICU dataset included SAPS II, APACHE II and SOFA for the first 24 hours after admission, length of mechanical ventilation, amount of administered blood products and the need for organ replacement therapy. Blood chemistry was registered at the time of initial emergency room management and after ICU admission (e. g., hemoglobin and lactate level, base excess, $\mathrm{pH}$, partial thromboplastin (PTT) and prothrombin time (PT) and International Normalized Ratio (INR)). Hemoglobin levels were also acquired 24 hours after ICU admission in order to detect possible bleeding situations.

The following were documented as outcome parameters: death within 24 hours after hospital admission, death during the trauma-associated hospital stay, death within 30 days, the occurrence of secondary bleeding, the detection of any trauma-associated damage in the AFS and surgical interventions within 24 hours.

\section{Radiographic data}

WBCT is basically defined as a non-enhanced native head CT followed by a contrast-enhanced thoracic, abdominal and pelvic CT including the whole spine [1]. Different multidetector CT scanners and different contrast media injection protocols are used in the clinical routine. Mostly the traditional segmental approach (the thorax is scanned in the angiographic phase and the abdomen is scanned in the portal venous phase) or the continuous angiographic approach are performed [23]. A good general overview of modern CT diagnostic methods in major trauma management is given by Huber-Wagner et al. [24].

At our institution two different scanners, scanning protocols and contrast media injection protocols were used. Between January 2008 and March 2011, all trauma scans were performed with a 64-row dual-source MDCT scanner (Sensation, Siemens Healthcare, Forchheim, Germany) and a monophasic scanning protocol. Since April 2011, all patients have been investigated with a 40-row sliding gantry computed tomography scanner (Sensation open, Siemens Healthcare, Forchheim, Germany) and a biphasic injection protocol. In most cases contrast medium (370 mg iodine/ mL; Ultravist 370, Bayer Healthcare, Berlin, Germany) was administered via an $18 \mathrm{G}$ peripheral access or through central venous access devices. Body weights, renal clearances, thyroid functions and history of possible contrast media reactions were not known in the emergency setting and had no impact on the examinations.

\section{Data sources and data management}

Clinical data was extracted from the patient data management system (PDMS) ICUData (IMESO ${ }^{\circledR} \mathrm{GmbH}$, Germany) and subsequently anonymized. Statistical analyses were performed with IBM $^{\circledR}$ SPSS $^{\circledR}$ Statistics (Version 22.0.0.0, IBM, Armonk, USA).

\section{Statistical analysis}

Due to the study design, statistical analysis was performed as a retrospective description of the study cohort. Clinical data was reviewed on plausibility and descriptive analyses were performed. Baseline characteristics were expressed as mean \pm standard deviation (SD) in normally distributed data and as median \pm interquartile range in not normally distributed data. For descriptive analysis of absolute and relative frequencies, contingency tables were used. In the frequency analysis, the $95 \%$ confidence intervals $(\mathrm{Cl})$ were calculated using Monte-Carlo statistics with bootstrap 1000 samples. If an event has not occurred, $\mathrm{Cl}$ was assumed for the calculation that the next event would have been positive (e. g., at 100 negative events (0/100), the estimated upper confidence interval (EUCI) was calculated as one positive of 101 events (1/101).

\section{Results}

During the study period, we identified 1129 emergency room patients who underwent WBCT examination. 73 pediatric patients, 661 patients with a negative WBCT result or missing AFS as well as 79 patients with an abdominal injury $(n=79)$ were excluded from the following investigation. The study cohort included 316 patients with an inconspicuous abdominal WBCT scan and an AFS scan performed within 24 hours after trauma.

\section{Patients characteristics}

The 316 included patients had a mean age of $43 \pm 19$ years, and $216(68.4 \%)$ were male. An initial GCS below 9 was present in 32 patients (10\%). The mean ISS was $10 \pm 8$ ( $\bullet$ Fig. 2 ). 74 patients (23.4\%) were classified a>s multiple trauma ("polytrauma", ISS $\geq 16$ ). The APACHE II, SOFA, and SAPS II were $11 \pm 8,3 \pm 3$, and $17 \pm 11$, respectively. The 30 -day mortality and overall hospital mortality were $1.8 \%$ and $1.9 \%$, respectively. None of the patients died during the first $24 \mathrm{~h}$ after hospital admission.

- Table 1 shows the demographic characteristics and laboratory and clinical findings reported for prehospital, emergency room, and ICU. The injury patterns were as follows: $16.1 \%$ (51)

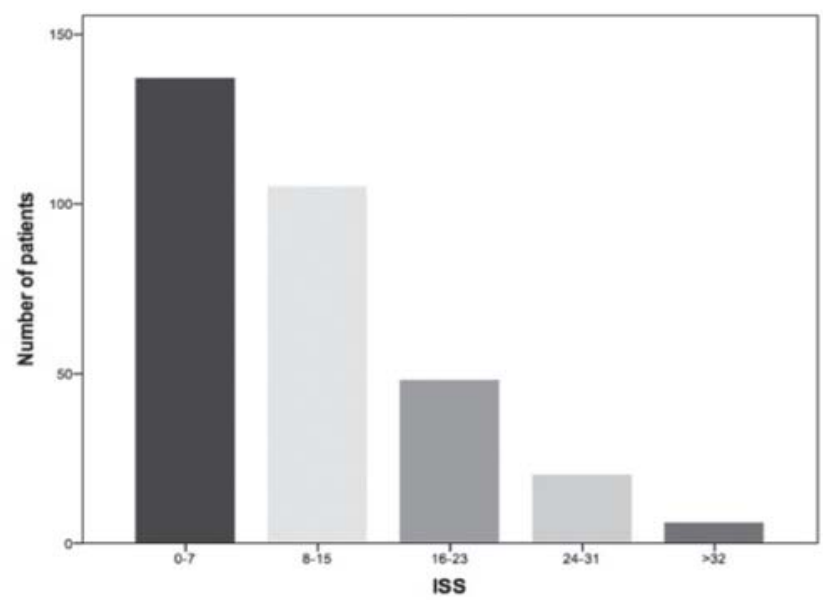

- Fig. 2 Bar graph presenting the injury severity score (ISS) of the study population.

- Abb. 2 Balkendiagramm zur Veranschaulichung des „injury severity score" (ISS) der Studienpopulation. 
injuries affected the face, $26.4 \%$ (83) the head or neck, $46.7 \%$ (148) the chest, $11 \%(35)$ the lower spine, $48.6 \%$ (154) the extremities or pelvic girdle. External injuries were present in $46.4 \%$ of cases. Detailed characterization of the subpopulation of multiple trauma patients featuring an ISS > 15 is presented in $\mathbf{~ T a b l e ~} 2$.

\section{Follow-up abdominal sonography}

All 316 included patients with an inconspicuous WBCT scan (absence of free intraabdominal fluid or abdominal parenchymal organ lesions) did not suffer from secondary intraabdominal bleeding or intraabdominal compartment syndrome or need intra-abdominal surgical or interventional procedures during the study period. A positive AFS scan was reported in 3 patients (0.9\%). Patient 1 (age 29 years, ISS 29, NISS 29) presented a limited amount of free intraabdominal fluid in the Morrison pouch, ventral to the liver, in the left lower abdomen around the sigmoid colon; patient 2 (age 36 years, ISS 14, NISS 22) showed a small anechoic signal inferior to the liver reconcilable with free intraabdominal fluid; and patient 3 (age 18 years, ISS 24, NISS 29) showed limited amounts of free intraabdominal fluid at different locations (Douglas cavity, beside the spleen and the liver and paracolic). All three patients had stable hemodynamic and respiratory status during the study period and none of the conspicuous AFS scans led to further treatment or surgical or interventional procedures. - Table 3 describes the examination results of patients with a positive AFS scan and patients who died during the hospital stay. None $(0.0 \%, \mathrm{EUCl}<1.3 \%)$ of these patients died during the first $24 \mathrm{~h}$ after hospital admission.

\section{Hospital mortality}

Six $(1.9 \%, \mathrm{Cl} 0.6-3.5 \%)$ patients died during their hospital stay, but none of these patients suffered from intraabdominal bleeding or organ lesion within the 24 hours after trauma ( $\vee$ Table 3 ). Only one $(0.3 \%, \mathrm{Cl} 0.0-1.0 \%)$ patient (age 62 years, ISS 22 , NISS 22) suffered from secondary bleeding, which was localized in the extraperitoneal fat tissue and caused by minor bleeding of the pelvic vasculature, within the first 24 hours after hospital admission. In this patient AFS did not show free intraabdominal fluid or parenchymal organ lesion. Subsequently, this patient needed surgical treatment of his subcutaneous hematoma on day 16 after trauma.

\section{Discussion}

AFS during tertiary trauma survey (TTS) was implemented in international trauma guidelines to reduce the rate of missed abdominal injuries [15-22]. Nonetheless, there is only poor evidence for the need for AFS as part of TTS, and the role of AFS is still unclear. Therefore, the aim of our study was to assess the impact of AFS within TTS in patients without parenchymal organ lesion or free intraabdominal fluid in the initial WBCT examination.

In this retrospective study with 316 patients, AFS, which was performed within 24 hours after WBCT, did not provide any additional information and had no impact on further treatment decisions. Summarized it can be noted:
First, we investigated a well-defined study population. Compared to the results of the trauma register of the German society of trauma surgery [21], our study cohort had equal patient characteristics concerning gender and age (male: $70 \%$ vs. $68 \%$, age: 47 years vs. 43 years) but showed different results for in-hospital mortality ( $10 \%$ vs. $2 \%$ ), mean ISS (17 vs. 10$)$, and ISS $\geq 16(48 \%$ vs. $23 \%$ ). In line with other parameters (e. g., length of stay in the hospital: $16 d$ vs. $13 d$, ICU length of stay: $7 d$ vs. $4 d$ ), these findings indicate a more severely injured patient collective described in the trauma register. Nevertheless, these results should be interpreted with caution, because the low mean ISS in our study is certainly caused by the study design with the exclusion of patients with parenchymal organ lesions or free intraabdominal fluid on the one hand, and on the other hand by the generous indication for trauma team activation defined by the German guideline on the treatment of severely injured patients ( $\vee$ Table 4) [1]. Moreover, this might also explain the varying percentages of severe head $(11.4 \%)$, chest $(27.8 \%)$ and extremity (16.1\%) injuries with an AIS $\geq 3$ compared to the German Society of Trauma Surgery registry. It is also well known that the sensitivity of injury severity prediction by a prehospital EMS provider is low $[22,25]$. Additionally, it should be kept in mind that trauma scores (e. g., AIS, ISS, NISS) could only be estimated after completion of sufficient diagnostics.

Second, WBCT is associated with a high sensitivity and specificity for the detection of intra-abdominal lesions after blunt abdominal trauma and is able to shorten the time between patient arrival and diagnosis [26, 27]. Livingston et al. [28] demonstrated a negative predictive value of $99 \%$ for WBCT and concluded that there are no advantages for prolonged surveillance or hospital admission after completion of a WBCT examination in patients with blunt abdominal trauma. Moreover, Huber-Wagner et al. [7] demonstrated that WBCT is a relevant and safe diagnostic tool even in hemodynamically unstable patients associated with increased survival even in severely injured patients. However, Neal et al. [29] controversially found a $70 \%$ higher mortality risk in patients who received an abdominal CT instead of instant laparotomy during initial emergency room management $(n=3.218)$. According to the results of Huber-Wagner et al. $[4,6]$ and the recommendations of the German Society of Trauma Surgery, WBCT is performed in all patients at risk for abdominal injury at our institution.

Third, focused assessment with sonography for trauma (FAST) is confirmed to be a safe, fast and highly specific diagnostic tool for abdominal screening in blunt trauma patients. Therefore, FAST is well implemented in current trauma guidelines. However, FAST only offers a low sensitivity regarding the detection of organ lesions and is also known as being highly examiner-dependent [30]. Moreover, FAST is limited by a sensitivity of $41 \%$ in hemodynamically stable patients (positive and negative predictive value $94 \%$ and $95 \%$ ) and should be reserved for hemodynamically unstable patients [31]. Compared to FAST, AFS is more time-consuming and needs a greater level of experience. In line with our investigation, Mauer et al. [20] stated that AFS is a time- and personnel-consuming diagnostic process which offers less additional information, often without any therapeutic consequences, but contributed a total cost of $29 €$ per patient. Therefore, its useful- 


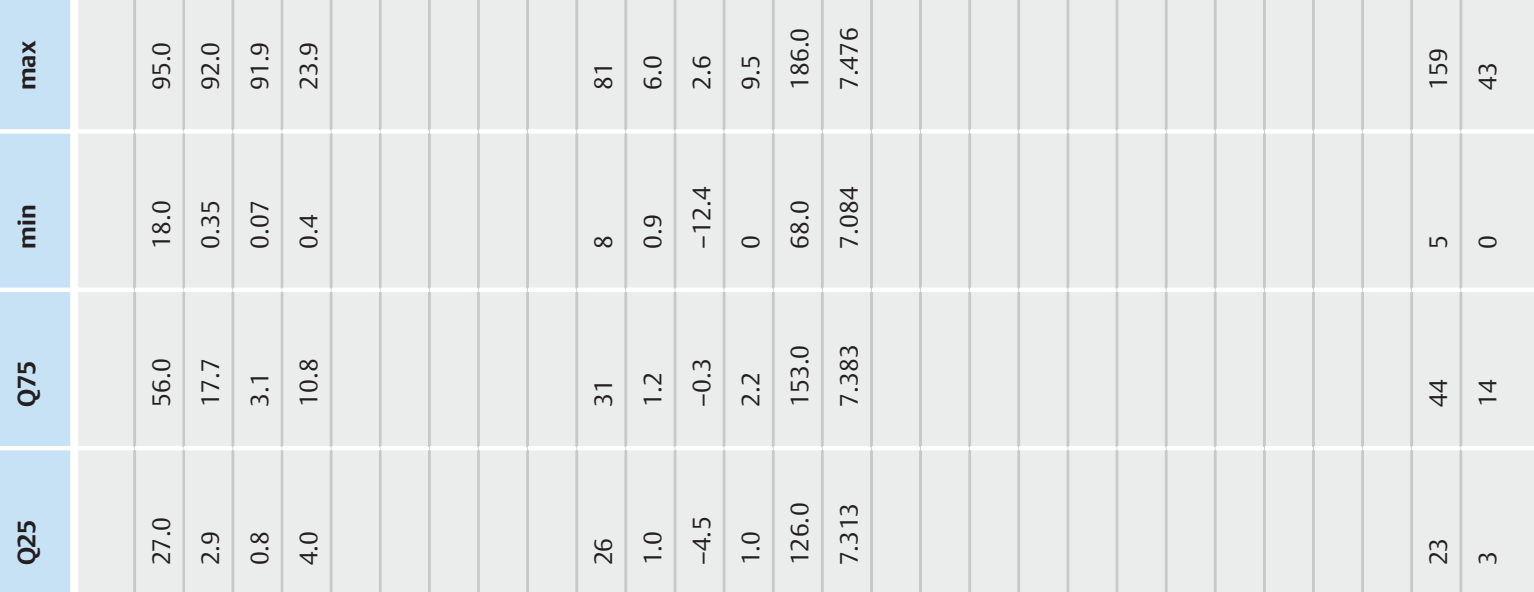

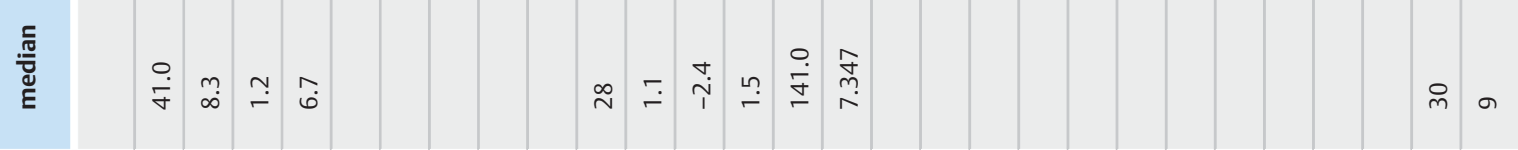

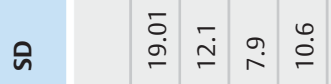
•
$\approx \infty$

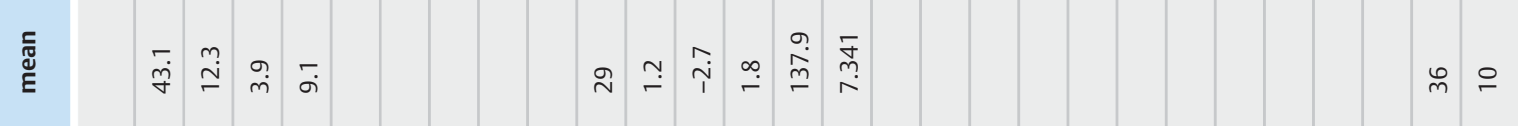

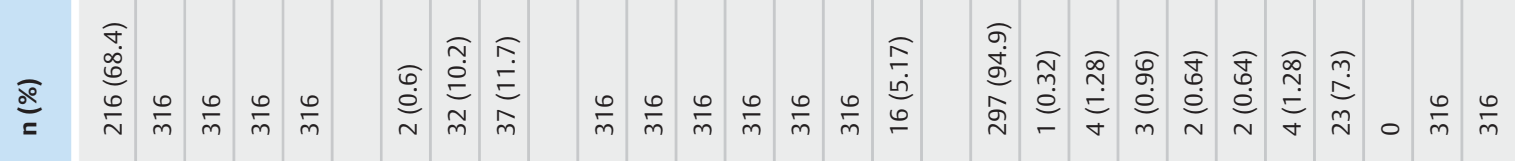

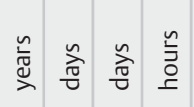

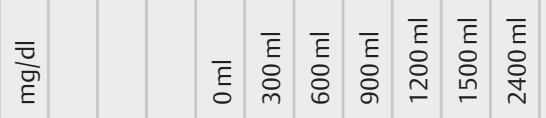

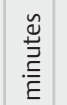

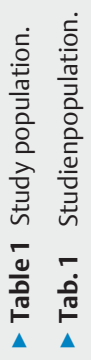
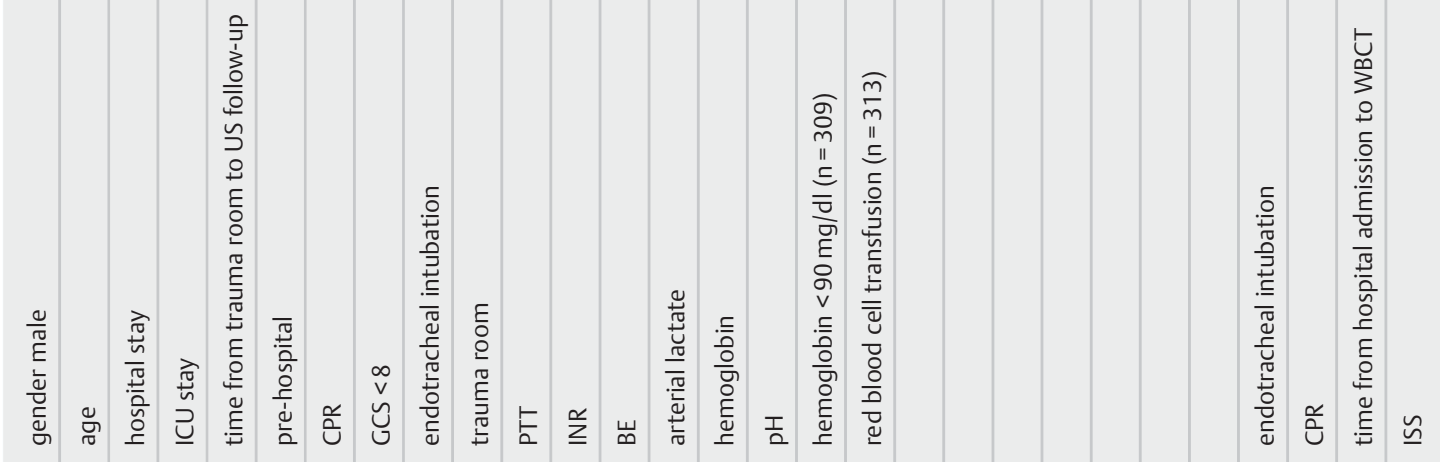


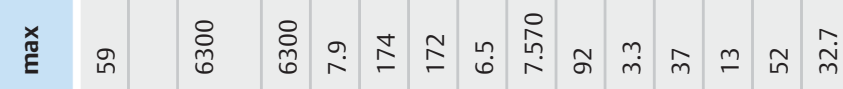

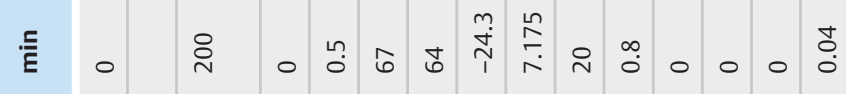

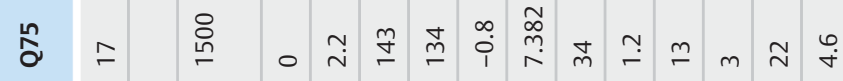

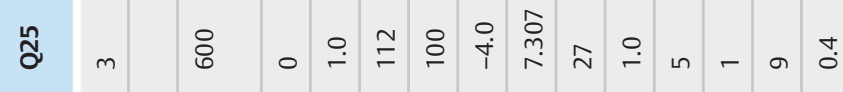

產

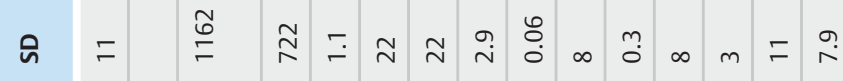

产

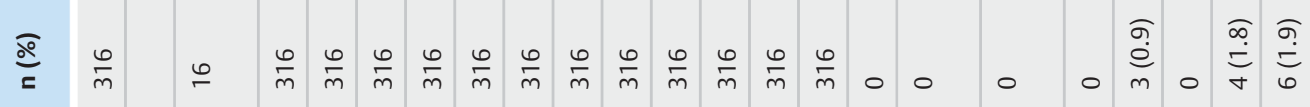

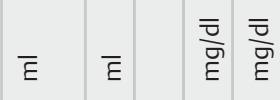

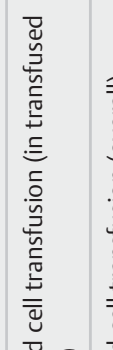

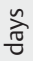

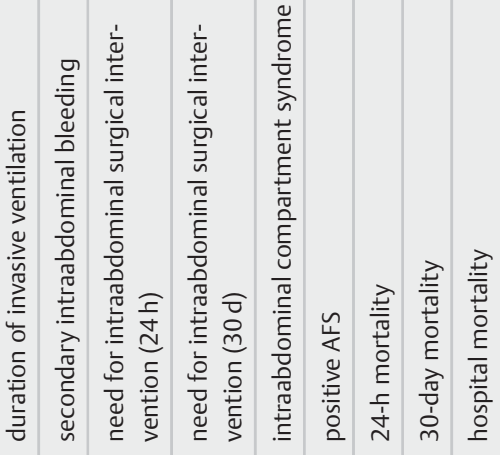

运言

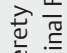

政

育获

芒远

窎总

खे خे

$\stackrel{\square}{\circ} \frac{0}{\circ}$

谉 $\frac{\overrightarrow{0}}{0}$

월

过

근

玄

茫

焉茛

艺总

过

旅

蒙隺

高

है 휸

亭 品

으

苫 $\stackrel{0}{\mathrm{E}}$

㱐

है

उั

高 $\frac{\pi}{\sqrt{0}}$

苍至

言

莺

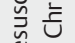

离

ते ते

틀 음

은 름

䜦 苞

峁京

芒岌

这

范

空

或

들

已̈

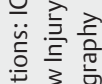

峁芯它 
- Table 2 Study characteristics of patients ISS > 15 .

- Tab. 2 Studiencharakteristiken der Patienten mit einem ISS $\geq 15$.

\begin{tabular}{|c|c|c|c|c|c|c|c|c|c|}
\hline & & $n(\%)$ & mean & SD & median & Q25 & Q75 & $\min$ & $\max$ \\
\hline gender male & & $57(77)$ & & & & & & & \\
\hline age & years & 74 & 46.1 & 20.65 & 45 & 24 & 62 & 18 & 83 \\
\hline ISS & & 74 & 23 & 6 & 22 & 17 & 27 & 16 & 43 \\
\hline NISS & & 74 & 27 & 9 & 24 & 22 & 29 & 16 & 59 \\
\hline APACHE II & & 74 & 16 & 9 & 14 & 8 & 24 & 2 & 37 \\
\hline SOFA & & 74 & 5 & 4 & 4 & 1 & 8 & 0 & 13 \\
\hline SAPS II & & 74 & 23 & 10 & 22 & 17 & 28 & 7 & 52 \\
\hline $\begin{array}{l}\text { secondary intraabdom- } \\
\text { inal bleeding }\end{array}$ & & 0 & & & & & & & \\
\hline $\begin{array}{l}\text { need for intraabdomin- } \\
\text { al surgical intervention } \\
(24 \mathrm{~h})\end{array}$ & & 0 & & & & & & & \\
\hline $\begin{array}{l}\text { need for intraabdomin- } \\
\text { al surgical intervention } \\
(30 \mathrm{~d})\end{array}$ & & 0 & & & & & & & \\
\hline $\begin{array}{l}\text { intraabdominal com- } \\
\text { partment syndrome }\end{array}$ & & 0 & & & & & & & \\
\hline positive AFS & & $2(2.7)$ & & & & & & & \\
\hline 24-h mortality & & 0 & & & & & & & \\
\hline 30-day mortality & & $2(3.3)$ & & & & & & & \\
\hline hospital mortality & & $4(5.4)$ & & & & & & & \\
\hline
\end{tabular}

Abbreviations: ISS: Injury Severity Score; NISS: New Injury Severity Score; APACHE II: Acute Physiology And Chronic Health Evaluation; SOFA: Sequential Organ Failure Assessment score; SAPS II: Simplified Acute Physiology Score; AFS: Abdominal Follow-Up Sonography

- Table 3 Cases of death.

- Tab. 3 Todesfälle.

\begin{tabular}{|c|c|c|c|c|}
\hline age & ISS & NISS & $\begin{array}{l}\text { day of death after } \\
\text { admission }\end{array}$ & cause of death \\
\hline 55 & 9 & 18 & 8 & hypoxic brain damage after aspiration and CPR \\
\hline 80 & 18 & 27 & 12 & pneumogenic sepsis with MOF after stabilized subdural hematoma \\
\hline 77 & 22 & 27 & 4 & subarachnoid hemorrhage with infaust prognosis \\
\hline 83 & 9 & 27 & 5 & cardiac and pulmonary failure after massive cerebral trauma \\
\hline 83 & 34 & 34 & 91 & $\begin{array}{l}\text { pneumogenic sepsis with acute renal failure after pulmonary contusion and critical } \\
\text { illness myopathy and neuropathy }\end{array}$ \\
\hline 74 & 17 & 27 & 31 & sepsis with MOF and cholecystitis after subdural hematoma \\
\hline
\end{tabular}

ness after WBCT has to be strongly questioned [31, 32]. Considering our results and in line with Geyer et al. [32], AFS within the TTS after inconspicuous WBCT examination and after exclusion of extra-abdominal bleeding sources should only be performed if clinical or laboratory findings in the observation period are indicative for patient deterioration. 
- Table 4 Criteria for trauma team activation based on the recommendations of the German Society of Trauma Surgery [1].

- Tab. 4 Kriterien der Trauma-Team Aktivierung gemäß der Empfehlungen der Deutschen Gesellschaft für Unfallchirurgie.

\section{mechanism of trauma}

high speed trauma ( $>80 \mathrm{~km} / \mathrm{h})$

fall from a height greater than 3 meters

passenger ejection out of a vehicle

death of another passenger

impaction of passenger

burial

pattern of injuries

multiple trauma (ISS > 15)

trauma to the head with disturbance of consciousness

trauma to the thorax with signs of instability

trauma with perforation of the thorax and abdomen

blunt abdominal trauma

trauma to the pelvis with signs of instability

fracture of more than one proximal bone

amputation of a proximal limb

vital signs

GCS $<14$

systolic blood pressure $<80 \mathrm{mmHg}$ after trauma

breathing frequency $<10 /$ min or $>29 /$ min after trauma

$\mathrm{SpO}_{2}<90 \%$ after trauma

admission from another treatment facility

prior trauma room treatment in another hospital

ICU admission < 96 hours after trauma in another hospital

incomplete diagnostics in another hospital after trauma

Abbreviations: ISS: Injury Severity Score; GCS: Glasgow Coma Scale; SpO2: mixed oxygen saturation; ICU: Intensive Care Unit

\section{Limitations}

Due to the fact that the evidence of this algorithm is only based on retrospective studies, its safety and efficiency have to be investigated in prospective studies.

In addition to its retrospective design, our study has some other limitations: The results of our retrospective analysis should be interpreted with caution because our study population represents only a subgroup of patients suffering from trauma. Therefore, the results and the derived recommendations cannot automatically be transferred to other patient collectives (e.g., patients with more severe trauma or parenchymal organ lesions). Also a higher number of cases and an analysis of other patient groups and subgroups will be necessary to answer the question regarding the need for AFS after trauma. Moreover, the results may be biased by the fact that only $30 \%$ of all patients with a negative
WBCT result regarding parenchymal organ lesion or free intra-abdominal fluid could be included in the study because an AFS scan was missing in 661 patients. It is to be expected that AFS frequently was not performed in hemodynamically stable patients with minor injuries without abdominal or pelvic pain or any other symptoms. One well-known general limitation is that AFS is highly dependent on operator skills, variability and experience, which certainly might have an impact on further diagnostics and therapy. Moreover the clinical status of intubated, demented or mentally impaired patients is difficult to evaluate and therefore clinical worsening might be overlooked by pure analysis of laboratory parameters. For this reason, the indication for AFS should be made more generously. Last of all, different CT scanners, scanning protocols and contrast media injection protocols were used in our study population and might therefore influence the diagnostic accuracy of WBCT. However, the multiple studies in the field of trauma scanning revealed high diagnostic accuracy independent of the CT scanner and contrast media injection protocol being used.

\section{Conclusion}

In conclusion, in this retrospective study, AFS as part of the TTS did not show additional benefits and had no impact on further treatment in patients without abdominal parenchymal organ lesions or free intraabdominal fluid in the initial WBCT examination. We conclude that AFS is not routinely required but should be performed if clinical or laboratory parameters require fast and noninvasive re-evaluation of the trauma patient.

\section{References}

[1] German Trauma Society (DGU). S3 - Guideline on Treatment of Patients with Severe and Multiple Injuries. Germany 2011; 012-019

[2] Spahn DR, Bouillon B, Cerny V et al. Management of bleeding and coagulopathy following major trauma: an updated European guideline. Crit Care 2013; 17: 76

[3] Rieger M, Czermak B, El Attal R et al. Initial clinical experience with a 64MDCT whole-body scanner in an emergency department: better time management and diagnostic quality?. J Trauma 2009; 66: 648-657

[4] Kanz KG, Paul AO, Lefering R et al. Trauma management incorporating focused assessment with computed tomography in trauma (FACTT) potential effect on survival. J Trauma Manag Outcomes 2010; 4: 4

[5] Surendran A, Mori A, Varma DK et al. Systematic review of the benefits and harms of whole-body computed tomography in the early management of multitrauma patients: Are we getting the whole picture? . J Trauma Acute Care Surg 2014; 76: 1122 - 1130

[6] Huber-Wagner S, Lefering R, Qvick LM et al. Effect of whole-body CT during trauma resuscitation on survival: a retrospective, multicentre study. Lancet 2009; 373: 1455-1461

[7] Huber-Wagner S, Biberthaler P, Häberle S et al. Whole-body CT in haemodynamically unstable severely injured patients-a retrospective, multicentre study. PLoS One 2013; 8: e68880

[8] Gupta M, Schriger DL, Hiatt JR et al. Selective use of computed tomography compared with routine whole body imaging in patients with blunt trauma. Ann Emerg Med 2011; 58: 407-416

[9] Ahvenjärvi L, Mattila L, Ojala R et al. Value of multidetector computed tomography in assessing blunt multitrauma patients. Acta Radiol 2005; 46: $177-183$

[10] Schoeneberg C, Schilling M, Keitel J et al. TraumaNetwork, Trauma Registry of th1. Schoeneberg, C. et al. TraumaNetwork, Trauma Registry of the DGU ${ }$, Whitebook, S3 Guideline on Treatment of Polytrauma/Severe 
Injuries - An Approach for Validation by a Retrospective Analysis of 2304 Patients (2002- 2011) of a Level 1 Trauma Centre. Zentralbl Chir DOI: $10.1055 / \mathrm{s}-0033-1360225$ Epub ahead of print 2014

[11] Pfeifer R, Pape HC. Missed injuries in trauma patients: A literature review. Patient Saf Surg 2008; 2: 20

[12] Lawson CM, Daley BJ, Ormsby CB et al. Missed injuries in the era of the trauma scan. J Trauma 2011; 70: 452-456

[13] Giannakopoulos GF, Saltzherr TP, Beenen LF et al. Missed injuries during the initial assessment in a cohort of 1124 level-1 trauma patients. Injury 2012; 43: 1517 - 1521

[14] Eurin M, Haddad N, Zappa M et al. Incidence and predictors of missed injuries in trauma patients in the initial hot report of whole-body CT scan. Injury 2012; 43: $73-77$

[15] Keijzers GB, Giannakopoulos GF, Del Mar C et al. The effect of tertiary surveys on missed injuries in trauma: a systematic review. Scand J Trauma Resusc Emerg Med 2012; 20: 77

[16] Leitlinien-Kommission der Deutschen Gesellschaft für Unfallchirurgie e. V. Leitlinie für die Unfallchirurgische Diagnostik und Therapie. Unfallchirurg 2001; 104: $902-912$

[17] Thomson CB, Greaves I. Missed injury and the tertiary trauma survey. Injury 2008; 39: $107-114$

[18] Mann V, Mann S, Szalay G et al. Treatment of polytrauma in the intensive care unit. Anaesthesist 2010; 59: 739-761

[19] Stürmer K, Dresing K, Bonnaire M. Recommended Guidelines for Diagnostics and Therapy in Trauma Surgery - Recommended Guidelines for Polytrauma. Eur J Trauma 2001; 27: 137 - 150

[20] Maurer MH, Winkler A, Wichlas F et al. Costs and role of ultrasound follow-up of polytrauma patients after initial computed tomography. Fortschr Röntgenstr 2012; 184: 53 - 58

[21] S. (NIS) und A.-A. der U. G. Deutsche Gesellschaft für Unfallchirurgie, Sektio für Notfall- und Intensivmedizin, “Jahresbericht 2013 des Traumaregisters der DGU”. 2013
[22] Muhm M, Danko T, Madler C et al. Preclinical prediction of prehospital injury severity by emergency physicians : approach to evaluate validity. Anaesthesist 2011; 60: 534-540

[23] Dreizin D, Munera F. Blunt polytrauma: evaluation with 64-section whole-body CT angiography. Radiographics 2012; 32: 609-631

[24] Huber-Wagner S, Kanz KG, Renger B et al. Moderne CT-Bildgebung im Rahmen der Schockraumversorgung Schwerverletzter. OUP 2015; 1: 28-37

[25] Bernhard M, Trautwein S, Stepan R et al. Prediction of further hospital treatment for emergency patients by emergency medical service physicians. Anaesthesist 2014; 63: 394-400

[26] Wurmb TE, Frühwald P, Hopfner W et al. Whole-body multislice computed tomography as the first line diagnostic tool in patients with multiple injuries: the focus on time. J Trauma 2009; 66: 658-665

[27] Wurmb TE, Quaisser C, Balling $\mathrm{H}$ et al. Whole-body multislice computed tomography (MSCT) improves trauma care in patients requiring surgery after multiple trauma. Emerg Med J 2011; 28: 300 - 304

[28] Livingston DH, Lavery RF, Passannante MR et al. Admission or observation is not necessary after a negative abdominal computed tomographic scan in patients with suspected blunt abdominal trauma: results of a prospective, multi-institutional trial. J Trauma 1998; 44: $273-280$

[29] Neal MD, Peitzman AB, Forsythe RM et al. Over reliance on computed tomography imaging in patients with severe abdominal injury: is the delay worth the risk?. J Trauma 2011; 70: 278-284

[30] Chiu WC, Cushing BM, Rodriguez A et al. Abdominal injuries without hemoperitoneum: a potential limitation of focused abdominal sonography for trauma (FAST). J Trauma 1997; 42: 617-623

[31] Natarajan B, Gupta PK, Cemaj S et al. FAST scan: is it worth doing in hemodynamically stable blunt trauma patients?. Surgery 2010; 148: 695 700

[32] Geyer LL, Körner M, Linsenmaier $U$ et al. The role of follow-up ultrasound and clinical parameters after abdominal MDCT in patients with multiple trauma. Acta Radiol 2014; 55: 486-494 